\title{
A PRESUNÇÃO DE INOCÊNCIA, A CONSTITUIÇÃO E O STF: COMENTÁRIOS AO HC 126.292/SP
}

\author{
THE PRESUMPTION OF INNOCENCE, THE CONSTITUTION AND THE STF : \\ COMMENTS TO HC 126,292 / SP
}

\begin{abstract}
Samantha Ribeiro Meyer-Pflug
Doutora e Mestre pela Pontifícia Universidade Católica de São Paulo - PUC/SP. Professora Permanente do Programa de Mestrado em Direito da UNINOVE. Coordenadora do Curso de Direito da mesma instituição. Membro do Conselho Superior de Estudos Jurídicos da Federação do Comércio. E-mail: samanthameyer@uol.com.br.
\end{abstract}

Mônica Bonetti Couto

Doutora e Mestre pela Pontifícia Universidade Católica de São Paulo - PUC/SP. Professora Permanente do Programa de Mestrado em Direito da UNINOVE. E-mail: monicabonetticouto@yahoo.com.br.

Convidadas

Doi: $10.5585 / \mathrm{rdb} . v 15 i 6.486$

RESUMO: Trata-se neste artigo de examinar com acuidade o teor do acórdão proferido pelo Supremo Tribunal Federal no Habeas Corpus n. 126.292 que aborda a aplicação do cumprimento de pena de prisão a partir da decisão proferida em segunda instância. O teor do referido acórdão entra em confronto direto com o teor da Constituição Federal de 1988 que é expressa ao estabelecer no seu art. 5 que trata dos direitos fundamentais, que ninguém será considerado culpado até o transito em julgado da decisão, ou seja, da decisão da qual não caiba mais recurso. Imperioso se faz analisar a compatibilidade entre a decisão proferido e o comando constitucional, bem como suas consequências no sistema jurídico pátrio.

Palavras-Chave: Princípio da presunção de inocência; controle de constitucionalidade; ativismo judicial.

ABSTRACT: It is in this article to examine accurately the content of the judgment of the Supreme Court in the Habeas Corpus n . 126292 which addresses the application of imprisonment of compliance from the decision rendered on appeal. The judgment content comes in direct confrontation with the Federal Constitution of the content 1988 is expressed to establish in your art. 5 which deals with fundamental rights, no one is guilty until the final and unappealable decision of the decision, ie the decision which does not fit more appeal. Imperious is done reviewing the implications of the decision and given the constitutional command, and its consequences on the Brazilian legal system.

Keywords: The presumption of innocence principle; judicial review; judicial activism. 
SUMÁRIO: Introdução; 1. A decisão comentada: O que o STF decidiu no HC 126.292; 2. Coisa julgada material versus efeitos da decisão/sentença: Institutos inconfundíveis; 3. A presunção de inocência assegurada no ART. 5. ํ, Inciso LVII, da CF; Conclusões; Referências.

\section{INTRODUÇÃO}

Pretende-se, por intermédio dessas linhas, trazer à luz algumas reflexões em torno da polêmica decisão proferida pelo Supremo Tribunal Federal, no âmbito do Habeas Corpus de n. ${ }^{\circ}$ 126.292, a qual, mudando a jurisprudência já firmada naquela E. Corte - e, de certo, ferindo de morte comando constitucional expresso -, passou a reconhecer a possibilidade/legitimidade da prisão antes do trânsito em julgado da sentença condenatória.

Trata-se de uma decisão da mais alta Corte do País que viola frontalmente a letra da Constituição que é enfática ao estabelecer que ninguém será considerado culpado até o transito em julgado da decisão. Em outras palavras, impõe-se uma decisão da qual não caiba mais recurso para se considerar alguém culpado pela justiça brasileira. Cumpre inicialmente analisar a circunstância de que a decisão não foi unanime e que posteriormente a publicação do acórdão, o Ministro Lewandowski proferiu decisão em sentido contrário.

Essa situação por si só suscita uma insegurança jurídica muito grande, bem como demonstra que a questão parece não estar pacificada no Supremo Tribunal Federal e deve ser novamente objeto de apreciação da Corte Suprema.

\section{A DECISÃO COMENTADA: O QUE O STF DECIDIU NO HC 126.292}

O Plenário do Supremo Tribunal Federal, ao negar o Habeas Corpus (HC) de n. ${ }^{\circ}$ 126.292, sob a relatoria do Ministro Teori Zavascki ${ }^{1}$ - e contrariando o seu entendimento, firme e reiterado ${ }^{2}$, em frontal colidência com texto expresso da Constituição - decidiu, por maioria de votos, pela possibilidade da execução da pena condenatória antes da ocorrência do trânsito em julgado.

Nestes termos, reconheceu que o início da execução da pena condenatória depois da confirmação da sentença em segundo grau não ofenderia o princípio constitucional da presunção da inocência, em julgamento que teve placar de maioria de votos (7 a 4), vencidos os Ministros Celso de Mello, Marco Aurélio, Ricardo Lewandowski e Rosa Weber.

De acordo com o que fez constar o relator do HC, Ministro Teori Zavascki, a manutenção da sentença penal pela segunda instância encerraria a análise de todos os fatos e provas que reconheceriam a culpa do condenado, o que autorizaria, segundo seu entendimento, o início da execução da pena. Constou de seu voto que:

(...) a execução da pena na pendência de recursos de natureza extraordinária não compromete o núcleo essencial do pressuposto da não culpabilidade, na medida em que o acusado foi tratado como inocente no curso de todo o

\footnotetext{
${ }^{1}$ HC 126.292/SP, Relator Ministro Teori Zavascki, acórdão disponibilizado no DJE de16.05.2016, Ata n. 71/2016. O acórdão encontra-se assim ementado: "CONSTITUCIONAL. HABEAS CORPUS. PRINCÍPIO CONSTITUCIONAL DA PRESUNÇÃO DE INOCÊNCIA (CF, art. 5. ${ }^{\circ}$, LVII). SENTENÇA PENAL CONDENATÓRIA CONFIRMADA POR TRIBUNAL DE SEGUNDO GRAU. EXECUÇÃO PROVISÓRIA. POSSIBILIDADE. 1. A execução provisória de acórdão penal condenatório proferido em grau de apelação, ainda que sujeito a recurso especial ou extraordinário, não compromete o princípio constitucional da presunção de inocência afirmado pelo art. 5. , inciso LVII da Constituição Federal. 2. Habeas Corpus denegado."

${ }^{2}$ Posição essa assumida pelo STF, no julgamento, pelo Plenário, do Habeas Corpus de n. 84.078/MG, realizado em 5/2/2009, oportunidade em que, por 7 a 4 votos, assentou-se que o princípio da presunção de inocência se mostra incompatível com a execução da sentença antes do trânsito em julgado da condenação.
}

Revista de Direito Brasileira | São Paulo, SP | v. 15 | n. 6 | p. 399 - 405 | set./dez. 2016 
processo ordinário criminal, observados os direitos e as garantias a ele inerentes, bem como respeitadas as regras probatórias e o modelo acusatório atual. Não é incompatível com a garantia constitucional autorizar, a partir daí, ainda que cabíveis ou pendentes de julgamento de recursos extraordinários, a produção dos efeitos próprios da responsabilização criminal reconhecida pelas instâncias ordinárias.

(...)

Nesse quadro, cumpre ao Poder Judiciário e, sobretudo, ao Supremo Tribunal Federal, garantir que o processo - único meio de efetivação do jus puniendi estatal -, resgate essa sua inafastável função institucional. A retomada da tradicional jurisprudência, de atribuir efeito apenas devolutivo aos recursos especial e extraordinário (como, aliás, está previsto em textos normativos) é, sob esse aspecto, mecanismo legítimo de harmonizar o princípio da presunção de inocência com o da efetividade da função jurisdicional do Estado.

Não se mostra arbitrária, mas inteiramente justificável, a possibilidade de o julgador determinar o imediato início do cumprimento da pena, inclusive com restrição da liberdade do condenado, após firmada a responsabilidade criminal pelas instâncias ordinárias... omissis.

Sustenta-se, com razão, que podem ocorrer equívocos nos juízos condenatórios proferidos pelas instâncias ordinárias. Isso é inegável: equívocos ocorrem também nas instâncias extraordinárias. Todavia, para essas eventualidades, sempre haverá outros mecanismos aptos a inibir consequências danosas para o condenado, suspendendo, se necessário, a execução provisória da pena. Medidas cautelares de outorga de efeito suspensivo ao recurso extraordinário ou especial são instrumentos inteiramente adequados e eficazes para controlar situações de injustiças ou excessos em juízos condenatórios recorridos. Ou seja: havendo plausibilidade jurídica do recurso, poderá o tribunal superior atribuir-lhe efeito suspensivo, inibindo o cumprimento de pena. Mais ainda: a ação constitucional do habeas corpus igualmente compõe o conjunto de vias processuais com inegável aptidão para controlar eventuais atentados aos direitos fundamentais decorrentes da condenação do acusado. Portanto, mesmo que exequível provisoriamente a sentença penal contra si proferida, o acusado não estará desamparado da tutela jurisdicional em casos de flagrante violação de direitos.

Merecem ser referidas as relevantíssimas lições que constam do voto do Ministro Celso de Mello, que, ao acompanhar a divergência aberta por Rosa Weber, consignou:

(...) o Supremo Tribunal Federal há de possuir a exata percepção de quão fundamentais são a proteção e a defesa da supremacia da Constituição para a vida do País, a de seu povo e a de suas instituições. A nossa Constituição estabelece, de maneira muito nítida, limites que não podem ser transpostos pelo Estado (e por seus agentes) no desempenho da atividade de persecução penal. Na realidade, é a própria Lei Fundamental que impõe, para efeito de descaracterização da presunção de inocência, o trânsito em julgado da condenação criminal. Veja-se, pois, que esta Corte, no caso em exame, está a expor e a interpretar o sentido da cláusula constitucional consagradora da presunção de inocência, tal como esta se acha definida pela nossa Constituição, cujo art. $5^{\circ}$, inciso LVII ("ninguém será considerado culpado até o trânsito em julgado de sentença penal condenatória"), estabelece, de modo inequívoco, que a presunção de inocência somente perderá a sua eficácia e a sua força normativa após o trânsito em julgado da sentença penal condenatória. É por isso que se mostra inadequado invocar-se a prática e a experiência registradas nos Estados Unidos da América e na França, entre outros Estados 
democráticos, cujas Constituições, ao contrário da nossa, não impõem a necessária observância do trânsito em julgado da condenação criminal. Mais intensa, portanto, no modelo constitucional brasileiro, a proteção à presunção de inocência. Quando esta Suprema Corte, apoiando-se na presunção de inocência, afasta a possibilidade de execução antecipada da condenação criminal, nada mais faz, em tais julgamentos, senão dar ênfase e conferir amparo a um direito fundamental que assiste a qualquer cidadão: o direito de ser presumido inocente até que sobrevenha condenação penal irrecorrível. Tenho para mim que essa incompreensível repulsa à presunção de inocência, Senhor Presidente, com todas as gravíssimas consequências daí resultantes, mergulha suas raízes em uma visão absolutamente incompatível com os padrões do regime democrático.

De fato, nota-se um grande clamor social em torno do tema, "exigindo-se" a prisão imediata dos condenados, para a eficácia do que se reconhece como um "combate à impunidade". 3

A grande questão que se coloca, porém, é a existência, no Brasil, de garantia fundamental de presunção de inocência (art. 5. ${ }^{\circ}$, inciso LVII, da Constituição Federal), a evidenciar a impropriedade - para se dizer o mínimo - desse novel entendimento.

Na mesma linha, aliás, consta da Declaração Universal de Direitos da Pessoa Humana, promulgada pela Assembleia Geral da ONU em 10 de dezembro de 1948, em seu art. 11 que todos presumem-se inocentes até que sobrevenha uma definitiva condenação judicial. ${ }^{4}$

Inteira razão assiste ao Ministro Celso de Mello que, na decisão em comento, quanto ao ponto, advertiu: "Mostra-se importante assinalar, neste ponto, Senhor Presidente, que a presunção de inocência, legitimada pela ideia democrática - não obstante golpes desferidos por mentes autoritárias ou por regimes autocráticos que absurdamente preconizam o primado da ideia de que todos são culpados até prova em contrário (!?!?) - tem prevalecido, ao longo de seu virtuoso itinerário histórico, no contexto das sociedades civilizadas, como valor fundamental e exigência básica de respeito à dignidade da pessoa humana."

Pode-se dizer, ademais, que aludida decisão acaba por baralhar conceitos absolutamente in fazer entre os conceitos de coisa julgada, trânsito em julgado e efeitos da decisão (sentença), como se procurará explanar logo adiante, ainda que de maneira bastante breve.

\section{COISA JULGADA MATERIAL VERSUS EFEITOS DA DECISÃO/SENTENÇA: INSTITUTOS INCONFUNDÍVEIS}

Convém ter presente, de pronto, o equívoco em que incorre a decisão sob nossos comentários, ao baralhar os institutos da coisa julgada material - e, portanto, de eventual

\footnotetext{
${ }^{3}$ Menciona-se, no voto do relator, a necessidade de um abrandamento da garantia constitucional da presunção de inocência com a "efetividade da função jurisdicional". Esse entendimento inclusive sugerir - se levado às últimas consequências - o que temos criticado, quanto a um panprincipioligismo exacerbado (expressão cunhada por Lênio Streck), com todos os males daí derivados, de um juiz justiceiro, que a pretexto de fazer justiça afasta-se, diminui ou suprimi garantias constitucionais. Eis a passagem a que nos referimos, deveras emblemática: "O tema relacionado com a execução provisória de sentenças penais condenatórias envolve reflexão sobre (a) o alcance do princípio da presunção da inocência aliado à (b) busca de um necessário equilíbrio entre esse princípio e a efetividade da função jurisdicional penal, que deve atender a valores caros não apenas aos acusados, mas também à sociedade, diante da realidade de nosso intricado e complexo sistema da justiça criminal."

4 " 1 . Toda a pessoa acusada de um acto delituoso presume-se inocente até que a sua culpabilidade fique legalmente provada no decurso de um processo público em que todas as garantias necessárias de defesa lhe sejam asseguradas."
}

Revista de Direito Brasileira | São Paulo, SP | v. 15 | n. 6 | p. 399 - 405 | set./dez. 2016 
ocorrência do trânsito em julgado - com o problema correlato aos efeitos da decisão ou sentença judicial impugnada.

$\mathrm{Na}$ passagem que nos interessa, constou do acórdão proferido pelo STF no HC 126.292/SP que "os dispositivos que sempre conferiram efeito apenas devolutivo aos recursos para as instâncias extraordinárias (art. 637 do CPP e art. 27, $\$ 2^{\circ}$, da Lei 8.038/1990, este último revogado pelo novo CPC - Lei 13.105/15 -, o qual, todavia, manteve o mesmo regime aos referidos recursos) legitimam a execução provisória da pena, sem, com isso, acarretar qualquer afronta ao princípio da presunção da inocência."

Ao que tudo indica, a confusão entre coisa julgada e a produção (ou não) de efeitos de uma dada sentença ou decisão judicial deita raízes na equivocada redação que o Código de Processo Civil de 1973 atribuiu à coisa julgada e, naturalmente, à doutrina que, sob a égide daquele revogado diploma, enquadrou-a como um dos efeitos gerados pela sentença (cf. art. 467 do CPC/73, com a seguinte redação: "Denomina-se coisa julgada material a eficácia, que torna imutável e indiscutivel a sentença, não mais sujeita a recurso ordinário ou extraordinário”).

Entretanto, como bem já havia registrado Liebman, a coisa julgada não é um efeito da sentença, nem com este pode ser confundida. É, sim, uma "qualidade" pela qual o efeito gerado pela sentença se manifesta, posto serem somente cinco os efeitos passíveis de serem gerados pela sentença de procedência: declaração, condenação, constituição, execução e mandamentalidade (ordem). ${ }^{5}$

Neste sentido, a coisa julgada há de ser entendida como uma qualidade ou autoridade de que se há de revestir a sentença da qual não cabia mais recursos - quer os ordinários, quer os extraordinários, dirigidos às instâncias superiores). Assim, aliás, estabelece a Lei de Introdução às Normas Brasileiras em seu art. $6^{\circ}, \S 3^{\circ}$ : "Chama-se coisa julgada ou caso julgado a decisão judicial de que já não caiba recurso”.

Corrigindo essa imprecisão conceitual, o Código de Processo Civil de 2015 substituiu a expressão eficácia por autoridade, estabelecendo em seu art. 502: "Denomina-se coisa julgada material a autoridade que torna imutável e indiscutível a decisão de mérito não mais sujeita a recurso."

\section{A PRESUNÇÃO DE INOCÊNCIA ASSEGURADA NO ART. 5. ${ }^{\circ}$, INCISO LVII, DA CF}

Não se pode concluir essas linhas sem retomar-se a análise do problema central - que consiste precisamente no núcleo da questão aqui debatida - concernente ao princípio da presunção de inocência, albergado que está no texto constitucional brasileiro como garantia expressa (art. 5. ${ }^{\circ}$, inciso LVII, "ninguém será considerado culpado até o trânsito em julgado de sentença penal condenatória;”).

É de extrema relevância lembrar que dentre as inúmeras inovações trazidas pelo novo Texto Constitucional, destaca-se o amplo tratamento conferido aos direitos e garantias fundamentais. A atual Constituição dedica seu Título II para o tratamento dos "Direitos e Garantias Fundamentais". A circunstância de o Texto Constitucional logo em seu Título II dispor sobre tais direitos e garantias, impõe de certa maneira que todo o sistema constitucional seja interpretado à luz desses direitos, pois eles são o cerne do Texto Constitucional e se irradiam pelo texto normativo.

$\mathrm{Na}$ atual Constituição referido título é dividido em cinco capítulos. O primeiro, que interesse diretamente ao tema aqui tratado, é destinado ao tratamento dos direitos e deveres individuais e coletivos. São os direitos de primeira dimensão, que são aqueles que se caracterizam por serem direitos do indivíduo oponíveis ao Estado e que prestigiam o homem

\footnotetext{
${ }^{5}$ Ver, por todos: Ada Pellegrini Grinover, Eficácia e autoridade da sentença penal. São Paulo: RT, 1978 e Thereza Alvim, Questões prévias e os limites objetivos da coisa julgada, São Paulo: RT, 1977.
}

Revista de Direito Brasileira | São Paulo, SP | v. 15 | n. 6 | p. 399 - 405 | set./dez. 2016 
enquanto indivíduo. ${ }^{6}$ Também são denominados de direitos negativos. Limitam o poder estatal, na medida em que proíbem ingerências "indevidas na esfera jurídica individual."7

$\mathrm{O}$ rol de direitos individuais e coletivos previstos no art. 5 do Texto Constitucional é meramente exemplificativo. ${ }^{8}$ Os direitos individuais são cláusulas pétreas, ou seja, não podem ser abolidos por Emenda à Constituição (art. 60, $\$ 4^{\circ}$, inc. IV). Trata-se de extensivo rol de direitos que se constituem numa verdadeira carta de direitos do cidadão. Houve um significativo aumento da previsão de direitos individuais em relação ao disposto na Constituição de 1967, bem como dos meios para garanti-los.

A dignidade da pessoa humana a despeito de não figurar expressamente no rol de direitos garantidos no art. $5^{\circ}$ da Constituição, constando apenas do art. $1^{\circ}$, III, na condição de fundamento da República, é erigida a condição de núcleo essencial dos direitos fundamentais permeando todo o texto constitucional, bem como a sua interpretação e aplicação ${ }^{9}$. Nesse sentido protege-se a dignidade humana em toda a sua extensão, bem como se veda expressamente a tortura e o tratamento degradante.

No âmbito penal, o Texto Constitucional elencou inúmeras garantias, dentre elas a que ninguém será processado nem sentenciado senão pela autoridade competente nem será privado da liberdade ou de seus bens sem o devido processo legal. ${ }^{10}$ Aos litigantes, em processo judicial ou administrativo, e aos acusados em geral são assegurados o contraditório e ampla defesa, com os meios e recursos a ela inerentes. Pela primeira vez na nossa história a Constituição expressamente não admite, no processo, as provas obtidas por meios ilícitos, trata-se de uma proteção aos direitos fundamentais.

Há menção expressa ao princípio da presunção de inocência, na medida em que, "ninguém será considerado culpado até o trânsito em julgado de sentença penal condenatória". Trata-se de um direito fundamental constitucionalmente assegurado ao indivíduo, consistente no fato de que somente será considerado culpado depois de uma decisão judicial na qual não comporte mais recurso. O intuito da norma constitucional foi o de exigir o esgotamento da via judicial para a declaração de culpa do indivíduo. Prestigia-se nesse sentido o exercício do direito à ampla defesa e contraditório em toda sua extensão.

Em virtude de o princípio da presunção de inocência estar assegurado na Constituição, não pode uma lei ordinária ou qualquer outro ato normativo dispor de maneira contrária ao seu conteúdo. Resta, vedada ainda qualquer tentativa no sentido de restringir o seu conteúdo ou a sua aplicação. Nesse contexto, tem-se que o acórdão proferido pelo Supremo Tribunal Federal sub examine viola o direito constitucionalmente assegurado. Vale frisar, mais uma vez, que se é uma garantia constitucional erigida a condição de clausula pétrea. No entanto, essa violação não é fácil de ser reparada, uma vez que tal decisão é oriunda do órgão de cúpula do Poder Judiciário e guardião da Constituição.

\footnotetext{
${ }^{6}$ Segundo Paulo Bonavides: "Os direitos da primeira geração são os direitos da liberdade, os primeiros a constarem do instrumento normativo constitucional, a saber, os direitos civis e políticos, que em grande parte correspondem, por um prisma histórico, àquela fase inaugural do constitucionalismo do Ocidente.

(...)

Os direitos da primeira geração ou direitos da liberdade têm por titular o indivíduo, são oponíveis ao Estado, traduzem-se como faculdades ou atributos da pessoa e ostentam uma subjetividade que é seu traço mais característico, são direitos de resistência ou de oposição perante o Estado." (BONAVIDES, Paulo. Curso de Direito Constitucional. São Paulo: Malheiros, 140 ed., 2004, p. 564)

${ }^{7}$ Cf. CANOTILHO, Joaquim José Gomes. Direito Constitucional e Teoria da Constituição, $6^{\circ}$ ed., Coimbra: Almedina, 2002., p. 407.

${ }^{8}$ Cf. MELlO FILHO, José Celso de. Constituição Federal Anotada. São Paulo: Saraiva, 2ed., 1986, p. 425.

9 Ver: MARTÍNEZ, Gregorio Peces-Barba. La dignidade de la persona desde la Filosofia del Derecho. In: Cuadernos “Bartolomé de Las Casas” n. 26, Madrid: Dykinson, 2002.

${ }^{10}$ Cf. CANOTILHO, Joaquim José Gomes. Op. Cit., p. 488.

Revista de Direito Brasileira | São Paulo, SP | v. 15 | n. 6 | p. 399 - 405 | set./dez. 2016
} 
Quer parecer que o Supremo Tribunal Federal no acordão sob comento incidiu no ativismo judicial, levando a efeito uma interpretação distinta do Texto Constitucional, na medida em considerou elementos outros que não a letra da norma. Imprescindível registrar que a letra da lei é o ponto de partida do interprete na busca do sentido e significado da norma, bem como o limite para sua atuação. Não se pode admitir uma interpretação contra legem. Ao proferir uma decisão que viola frontalmente o conteúdo da norma constitucional, extrapola a Corte Suprema os limites de sua atuação, alçando-se assim a condição de legislador constituinte.

Contudo, a questão ainda será objeto de nova decisão, uma vez que alguns Ministros do Supremo Tribunal Federal estão proferindo decisões monocráticas em consonância com a norma constitucional. Faz-se imprescindível a reapreciação da matéria para fixar o entendimento do Supremo Tribunal Federal sobre a questão, bem como garantir a segurança jurídica.

\section{CONCLUSÕES}

Ao analisar o conteúdo do art. 5. ${ }^{\circ}$, inciso LVII, da Constituição Federal, percebe-se, com alguma nitidez, que tal preceito assegura e consagra o princípio da presunção de inocência (ou, como querem alguns, princípio da não culpabilidade) até o trânsito em julgado da decisão condenatória.

Disso emerge a impossibilidade de considerar-se culpada qualquer pessoa antes do trânsito em julgado da decisão - e, neste sentido, imputar-lhe os efeitos dessa futura e ainda virtual condenação, como por exemplo, o mais evidente efeito é a sua prisão fora das situações previstas (prisão cautelar ou preventiva, por exemplo). É dizer, antes da condenação "passar em julgado", o que se verifica quando a sentença não está mais sujeita a recurso, ordinário ou extraordinário.

Temos para nós que a inversão dessa lógica, com a permissão da prisão antes mesmo do trânsito em julgado, contraria e fere de morte o postulado constitucional erigido ao status de garantia (art. 5. ${ }^{\circ}$, inciso LVII) e, de quebra, ameaça uma das bases mais notáveis de conquistas de um Estado que se afirma Democrático de Direito.

\section{REFERÊNCIAS}

ALVIM, Thereza Alvim. Questões prévias e os limites objetivos da coisa julgada, São Paulo: RT, 1977.

BONAVIDES, Paulo. Curso de Direito Constitucional. São Paulo: Malheiros, 140 ed., 2004.

CANOTILHO, Joaquim José Gomes. Direito Constitucional e Teoria da Constituição, $6^{\circ}$ ed., Coimbra: Almedina, 2002.

GRINOVER, Ada Pellegrini., Eficácia e autoridade da sentença penal. São Paulo: RT, 1978.

MARTÍNEZ, Gregorio Peces-Barba. La dignidade de la persona desde la Filosofia del Derecho. In: Cuadernos "Bartolomé de Las Casas” n. 26, Madrid: Dykinson, 2002.

MELlO FILHO, José Celso de. Constituição Federal Anotada. São Paulo: Saraiva, 2ed., 1986. 